\title{
Accuracy of sonographic fetal weight estimation in full-term singleton pregnant women
}

\author{
Emre Erdem Tas ${ }^{1}$, Edip Alptug Kir', \\ Gamze Yilmaz ${ }^{3}$, Ayse Filiz Yavuz ${ }^{4}$
}

\begin{abstract}
Objectives: To investigate the factors which might influence the sonographic fetal weight estimation (SFWE) accuracy.

Methods: This prospective study was conducted among 949 singleton term pregnant women who delivered at a tertiary center, from January 2017 to December 2017. All participants' maternal (i.e. parity, age, body mass index and gestational weight gain during pregnancy), fetal sonographic (i.e. fetal presentation, amniotic fluid index, localization of placenta and estimated fetal weight) and neonatal (birth weight and gender) characteristics were recorded. A $p<0.05$ was considered significant.

Results: The mean absolute percent error (APE) values of SFWE was $8.2 \pm 6.5$ percent, and overall failure ratio (APE $>10 \%$ ) was $33 \%$. In failure group, primiparous woman and cephalic presentation fetus were significantly more common compared to accuracy group (55.9\% vs.44.8\%; $p=0.001$ and $98 \%$ vs. $95.2 \%$; $p=0.03$, respectively). In contrast, the mean neonatal birth weight (NBW) value was significantly lower in failure group compared to success group $(3250 \pm 565$ gr vs. $3404 \pm 410 \mathrm{gr} ; p=0.001)$. The correlation between SFWE and NBW was linear, however negative, and significant $(p=0.001)$. Logistic regression analysis revealed that primiparous woman, cephalic presentation fetus and $<3300 \mathrm{gr}$ NBW were independent risk factors for the SFWE failure (relative risks were 1.6, 2.8 and 2.4 respectively, $p<0.05$ ).

Conclusion: SFWE has a high correlation with NBW, however it's accuracy is still unsatisfactory, and depend on many unpredictable and inconsistent factors.
\end{abstract}

KEYWORDS: Prenatal ultrasonography, fetal weight, Birth weight, Pregnancy.

doi: https://doi.org/10.12669/pjms.35.1.373

How to cite this:

Tas EE, Kir EA, Yilmaz G, Yavuz AF. Accuracy of sonographic fetal weight estimation in full-term singleton pregnant women. Pak J Med Sci. 2019;35(1):34-38. doi: https://doi.org/10.12669/pjms.35.1.373

This is an Open Access article distributed under the terms of the Creative Commons Attribution License (http://creativecommons.org/licenses/by/3.0), which permits unrestricted use, distribution, and reproduction in any medium, provided the original work is properly cited.

1. Emre Erdem Tas,

Assistant Professor,

2. Edip Alptug Kir, M.D.

3. Gamze Yilmaz, M.D.

Department of Obstetrics and Gynecology,

Ankara Ataturk Training and Research Hospital, Ankara, Turkey.

4. Prof. Ayse Filiz Yavuz,

1,2,4: Department of Obstetrics and Gynecology,

Ankara Yildirim Beyazit University, Faculty of Medicine, Ankara, Turkey.

Correspondence:

Emre Erdem Tas,

Assistant Professor, Department of Obstetrics and Gynecology,

Ankara Yildirim Beyazit University, Ankara Ataturk Training and Research Hospital, Mehmet Akif Ersoy Mah,

Yesilay Cad. 5A/121, 06200 Yenimahalle/Ankara, Turkey.

E-mail: doctortas@yahoo.com

* Received for Publication:

August 20, 2018

* Edited and Corrected:

* Accepted for Publication:

\section{INTRODUCTION}

Birth weight is an important factor determining maternal and neonatal well-being that significantly influences obstetric management. ${ }^{1}$ Hence, fetal weight estimation has become an important aspect of examinations in the late period of pregnancy. To this end, various techniques, including clinical examinations, such as Leopold's maneuvers, ${ }^{2}$ sonography, ${ }^{3}$ and magnetic resonance imaging, ${ }^{4}$ have been used. However, sonography has become the most common method for estimating fetal weight worldwide, because of its objectivity and ease of use.

It is still debated whether sonography is a reliable tool for estimating fetal weight accurately. ${ }^{5,6}$ In previous studies, ${ }^{4,7,8}$ the accuracy of sonographic fetal weight estimation (SFWE), which is regarded 
by many as a determinant of fetal weight within a $10.0 \%$ error of neonatal birth weight (NBW), has varied widely. ${ }^{9,10}$ Moreover, in a quantitative review, ${ }^{8}$ the mean accuracy rate of SFWE was reported to be $56.0 \%$ in full-term pregnant women. Evaluating the validity of sonography, previous studies ${ }^{8,11-19}$ have also evaluated whether maternal, fetal sonographic, neonatal, and technical characteristics play a role in determining the accuracy of SFWE. However, the results have been inconsistent and it is not yet known which factor(s) increase prediction failure. ${ }^{5}$ Therefore, the aim of this study was to investigate the accuracy, as well as factors affecting the accuracy, of SFWE in fullterm uncomplicated singleton pregnant women.

\section{METHODS}

We conducted a prospective cohort study of full-term singleton pregnant women who were admitted to the Obstetrics and Gynecology Unit of a university hospital between January and December 2017. All participants provided informed written consent. This study was approved by the Ethical Review Board Committee of our institution (approval no.: 26379996/125). Research was conducted in accordance with the World Medical Association Declaration of Helsinki, revised in 2000, Edinburgh.

Patients with congenital malformations of the fetus, placental abnormalities, maternal medical conditions, or pregnancies complicated by stillbirths were excluded from the study to ensure objectivity of the data. In the study group, maternal (age, parity [primiparity vs. multiparity], gestational age [weeks], height $[\mathrm{cm}]$, antepartum weight $[\mathrm{kg}]$, weight gain during pregnancy $[\mathrm{kg}]$, body mass index, and stage of labor at sonographic examination [active phase vs. latent phase]), fetal sonographic (SFWE [g], amniotic fluid volume [mm], placental localization [anterior vs. other]), and neonatal (NBW [g] and sex) characteristics of the participants were recorded during the study period. Body mass index $\left(\mathrm{kg} / \mathrm{m}^{2}\right)$ was calculated as the antepartum weight in kilograms divided by the height in meters squared.

The sonographic examinations were performed using Esaote My Lab 60 (Esaote, Genova, Italy) and a $3.5-\mathrm{MHz}$ curvilinear probe. Fetal measurements included biparietal diameter, abdominal circumference, and femur length. For each patient, the measurements were repeated three times and the average values were recorded for analysis. Thereafter, SFWE was calculated using Hadlock's formula: $\log _{10}$ birth weight $=1.335-(0.0034 \times$ abdominal circumference $\times$ femur length $)+(0.0316 \times$ biparietal diameter $)+(0.0457 \times$ abdominal circumference $)+$ $(0.1623 \times$ femur length $){ }^{20}$ Additionally, amniotic fluid volume, which was measured in all four quadrants, and placental localization were recorded.

Training practitioners have been associated with increased SFWE accuracy and prolonged time intervals between examination and delivery have been associated with reduced SFWE accuracy. ${ }^{12,13}$ Therefore, all sonographic examinations were performed by two experienced obstetricians (E.E.T. and A.F.Y.) during hospital admission. If delivery did not occur within one week of admission, the sonographic examinations were repeated by the same obstetricians. Concurrent to the sonographic examinations, vaginal examinations were performed by the same obstetricians. Patients were classified according to the stage of labor: active (cervical dilation $\geq 4.0 \mathrm{~cm}$ ) or latent (cervical dilation $<4.0 \mathrm{~cm}$ ) phase.

The main standard for comparing SFWE was NBW, which is measured after birth by midwives using a digital scale. SFWE accuracy was analyzed using the percentage error ([estimated weight actual weight] $\times 100 /$ actual weight), although the absolute percentage error (APE) was used for the statistical analysis. If the APE fell within the 10.0\% range, SFWE was considered a success; if not, SFWE was considered a failure. Patients were grouped according to SFWE accuracy (i.e., success $v$ s. failure) and compared in relation to the investigated parameters to determine factors associated with SFWE failure.

Statistical Analyses: Descriptive parameters were expressed as the mean and standard deviation (continuous variables) and as numbers and percentages (categorical variables). Independent samples $t$-tests and Chi-square tests were used to analyze the data and compare the groups (i.e., success vs. failure). The relationship between NBW and the APE of SFWE accuracy was evaluated using Pearson's correlation coefficient. Thereafter, receiver operating characteristic curve analysis was used to determine cutoff values of NBW for predicting an increased risk of SFWE failure. Variables with a $p<0.05$ were included in the binary logistic regression analysis and the influence of each factor on the accuracy of SFWE was evaluated. Statistical analyses were conducted using Statistical Package for the Social Sciences for Windows (software version 21.0; IBM Corp., Armonk, NY, USA). A $p<0.05$ was considered statistically significant. Relative Risk (RR) and 95.0\% Confidence Intervals (CIs) were calculated. 


\section{RESULTS}

During the study period, 949 (74.3\%) of the 1,278 women with full-term singleton pregnancies fulfilled the inclusion criteria and were enrolled into the study. In the study group, the mean absolute error and mean APE was $269 \pm 212 \mathrm{~g}$ and $8.2 \pm 6.5 \%$, respectively. The APE was $>10.0 \%$ in 313 patients. The overall failure rate was $33.0 \%$. The maternal, fetal sonographic, and neonatal characteristics of the patients are summarized in Table-I.

Except for the mean NBW, fetal presentation, and parity, the groups did not differ according to the investigated parameters (Table-II). Primiparity and cephalic presentation of the fetus were significantly more common in the failure group than in the success group $(55.9 \%$ [175/313] vs. $44.8 \%$ [285/636] and $98.1 \%[307 / 313]$ vs. $95.2 \%$ [606/636]; $p=0.001$ and $p=0.030$, respectively). Conversely, the mean

Table-I: Maternal, fetal sonographic, and neonatal characteristics of the patients.

\begin{tabular}{|c|c|}
\hline Characteristic & Patients $(n=949)$ \\
\hline \multicolumn{2}{|l|}{ Maternal } \\
\hline Age (years), mean \pm SD & $28.1 \pm 5.4$ \\
\hline \multicolumn{2}{|l|}{ Parity, $n(\%)$} \\
\hline Primiparity & $460(48.4)$ \\
\hline Multiparity & $489(51.6)$ \\
\hline Gestational age (weeks), mean \pm SD & $39.1 \pm 1.3$ \\
\hline Maternal height $(\mathrm{cm})$, mean \pm SD & $161.7 \pm 5.3$ \\
\hline $\begin{array}{l}\text { Maternal pregestational weight }(\mathrm{kg}) \\
\text { mean } \pm \text { SD }\end{array}$ & $65.0 \pm 12.4$ \\
\hline BMI (kg/m2), mean \pm SD (range) & $29.2 \pm 4.8$ \\
\hline $\begin{array}{l}\text { Weight gain during pregnancy }(\mathrm{kg}) \text {, } \\
\text { mean } \pm S D\end{array}$ & $11.3 \pm 4.5$ \\
\hline \multicolumn{2}{|l|}{ Labor stage, $n(\%)$} \\
\hline Active phase & $114(12.0)$ \\
\hline Latent phase & $835(88.0)$ \\
\hline \multicolumn{2}{|l|}{ Fetal sonographic } \\
\hline Estimated fetal weight $(\mathrm{g})$, mean $\pm \mathrm{SD}$ & $3,430 \pm 360$ \\
\hline Amniotic fluid volume $(\mathrm{mL})$, mean $\pm \mathrm{SD}$ & $104 \pm 34$ \\
\hline \multicolumn{2}{|l|}{ Placental localization, $n(\%)$} \\
\hline Anterior & $286(30.1)$ \\
\hline Other (posterior, fundal, or lateral) & $663(69.9)$ \\
\hline \multicolumn{2}{|l|}{ Fetal presentation, $n(\%)$} \\
\hline Cephalic & $913(96.2)$ \\
\hline Non-cephalic (breech or transverse) & $36(3.8)$ \\
\hline \multicolumn{2}{|l|}{ Neonatal } \\
\hline \multicolumn{2}{|l|}{ Sex, $n(\%)$} \\
\hline Male & $514(54.2)$ \\
\hline Female & $435(45.8)$ \\
\hline NBW $(g)$, mean \pm SD & $3,354 \pm 470$ \\
\hline
\end{tabular}

Abbreviations: BMI, body mass index; NBW, neonatal birth weight; SD, standard deviation.

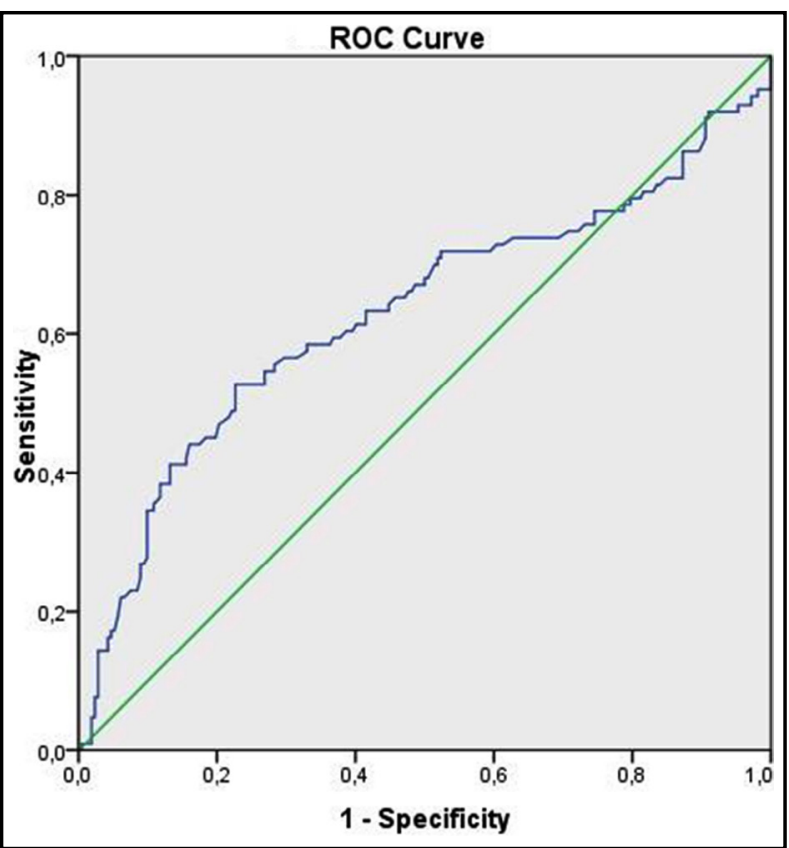

Fig.1: Receiver operating characteristic (ROC) curve of neonatal birth weight for determining sonographic fetal weight estimation accuracy (i.e., success vs. failure) (area under the curve: 0.63 , standard error: 0.02 ).

NBW was significantly lower in the failure group than in the success group $(3,250 \pm 565$ vs. 3,404 \pm 410 $\mathrm{g}$, respectively; $p=0.001$ ). There was a significant negative linear correlation between the APE and NBW (Pearson's correlation coefficient, $p=0.001$ ). Receiver operating characteristic curve analysis revealed that the optimal cutoff value of NBW for discriminating between the groups was $3,300 \mathrm{~g}$. The sensitivity was $60.0 \%$ and the specificity was $61.0 \%$ (Fig.1).

Finally, binary logistic regression analysis identified primiparity (RR: 1.6, 95.0\% CI: 1.2 to 2.1; $p=0.010$ ), cephalic presentation of the fetus (RR: 2.8, 95.0\% CI: 1.1 to $6.8 ; p=0.020$ ), and a NBW of $<3,300$ g (RR: $2.4,95.0 \%$ CI: 1.8 to 3.2; $p=0.010$ ) as independent risk factors for SFWE failure.

\section{DISCUSSION}

SFWE is significantly correlated with NBW. Previous reports ${ }^{6,8,14,21-23}$ investigating the efficiency of sonography have determined that the mean APE is within a $10.0 \%$ range of NBW. However, SFWE accuracy remains unsatisfactory, with failure rates of between $32.0 \%$ and $83.0 \% .{ }^{9,10}$ The overall accuracy rate of SFWE has been reported to be $56.0 \%$ in fullterm pregnant women. ${ }^{8}$ In this study, the mean APE was $8.2 \%$ and the SFWE accuracy rate was $67.0 \%$. These findings were consistent with those of previous reports. $6,8-10,14,21-23$ 
Table-II: Maternal, fetal sonographic, and neonatal characteristics according to sonographic fetal weight estimation accuracy (i.e., success vs. failure).

\begin{tabular}{|c|c|c|c|}
\hline \multirow[t]{2}{*}{ Characteristic } & Success & Failure & \multirow[t]{2}{*}{$p$-value } \\
\hline & $(n=636,67.0 \%)$ & $(n=313,33.0 \%)$ & \\
\hline \multicolumn{4}{|l|}{ Maternal } \\
\hline Age (years), mean \pm SD & $28.2 \pm 5.4$ & $27.9 \pm 5.4$ & 0.570 \\
\hline \multicolumn{4}{|l|}{ Parity, $n(\%)$} \\
\hline Primiparity & $285(30.0)$ & $175(18.4)$ & 0.001 \\
\hline Multiparity & $351(37.0)$ & $138(14.6)$ & \\
\hline Gestational age (weeks), mean \pm SD & $39.1 \pm 1.3$ & $39.0 \pm 1.2$ & 0.330 \\
\hline Maternal height $(\mathrm{cm})$, mean \pm SD & $161.8 \pm 5.5$ & $161.5 \pm 4.8$ & 0.350 \\
\hline Maternal pregestational weight $(\mathrm{kg})$, mean \pm SD & $64.8 \pm 12.6$ & $65.3 \pm 12.0$ & 0.570 \\
\hline $\mathrm{BMI}\left(\mathrm{kg} / \mathrm{m}^{2}\right)$, mean $\pm \mathrm{SD}$ & $29.1 \pm 4.9$ & $29.1 \pm 4.5$ & 0.950 \\
\hline Weight gain during pregnancy $(\mathrm{kg})$, mean $\pm \mathrm{SD}$ & $11.5 \pm 4.8$ & $10.9 \pm 3.9$ & 0.060 \\
\hline \multicolumn{4}{|l|}{ Labor stage, $n(\%)$} \\
\hline Active phase & $114(12.0)$ & $57(6.0)$ & 0.930 \\
\hline Latent phase & $522(55.0)$ & $256(27.0)$ & \\
\hline \multicolumn{4}{|l|}{ Fetal sonographic } \\
\hline Estimated fetal weight $(\mathrm{g})$, mean \pm SD & $3,415 \pm 360$ & $3,460 \pm 360$ & 0.070 \\
\hline Amniotic fluid volume $(\mathrm{mL})$, mean \pm SD & $105 \pm 36$ & $103 \pm 31$ & 0.640 \\
\hline \multicolumn{4}{|l|}{ Placental localization, $n(\%)$} \\
\hline Anterior & $180(18.9)$ & $106(11.2)$ & 0.080 \\
\hline Other (posterior, fundal, or lateral) & $456(48.1)$ & $207(21.8)$ & \\
\hline \multicolumn{4}{|l|}{ Fetal presentation, $n(\%)$} \\
\hline Cephalic & $606(63.9)$ & $307(32.3)$ & \\
\hline Non-cephalic (breech or transverse) & $30(3.2)$ & $6(0.6)$ & 0.030 \\
\hline \multicolumn{4}{|l|}{ Neonatal } \\
\hline \multicolumn{4}{|l|}{ Sex, $n(\%)$} \\
\hline Male & 348 (36.7) & $166(17.5)$ & 0.620 \\
\hline Female & $288(30.3)$ & $147(15.5)$ & \\
\hline NBW $(g)$, mean \pm SD & $3,404 \pm 410$ & $3,250 \pm 565$ & 0.001 \\
\hline
\end{tabular}

Abbreviations: BMI, body mass index; NBW, neonatal birth weight; SD, standard deviation.

It has not yet been established whether factors relating to maternal, fetal sonographic, and neonatal characteristics are responsible for SFWE failure. Our findings support this position. For instance, in contrast to previous studies, ${ }^{11,14-16,18,19}$ we did not identify high maternal body mass index, low amniotic fluid volume, macrosomia, female fetus, high maternal height, and older age as risk factors for SFWE failure. Moreover, there were no significant associations between maternal antenatal weight, weight gain during pregnancy, placental localization (anterior vs. other), and stage of labor (active vs. latent phase) and SFWE failure.

In the present study, primiparity and cephalic presentation of the fetus were independent risk factors for SFWE failure, with RRs of 1.6 and 2.8, respectively. In contrast to the present study, no significant associations have been identified between parity and fetal presentation and SFWE failure in recent reports. ${ }^{19,24}$ Because no comparable data were presented in these studies, we could not determine the cause of dissimilarity between the findings of these studies and our own.

In the present study, there was, however, a significant negative linear correlation between the mean APE and NBW. A NBW of $<3,300 \mathrm{~g}$ was identified as an independent risk factor for SFWE failure. Below this value, the RR was 2.4 times greater. In contrast to the present study, Colman et al. ${ }^{23}$ failed to identify any significant associations between the mean APE and SFWE failure and NBW in a study population comparable to ours. The inconsistency between studies may be the result of many unpredictable factors in the study population, such as race, practitioner experience, and whether the characteristics were investigated in our study.

\section{CONCLUSIONS}

In conclusion, although the present study has its strengths (the prospective study design and taking 
into consideration the technical characteristics) and limitations (single-center study on uncomplicated pregnant women), it revealed a significant association between SFWE and NBW. Conversely, our study showed that SFWE accuracy remains unsatisfactory and is dependent on unpredictable and inconsistent factors.

Acknowledgements: Editage (www.editage.com) for English language editing.

Financial disclosure: None.

Declarations of interest: None.

\section{REFERENCES}

1. Yu J, Flatley C, Greer RM, Kumar S. Birth-weight centiles and the risk of serious adverse neonatal outcomes at term. Perinat Med 2017. pii:/j/jpme.ahead-of-print/jpm-20170176/jpm-2017-0176.xml. doi: 10.1515/jpm-2017-0176.

2. Kesrouani A, Atallah C, AbouJaoude R, Assaf N, Khaled $\mathrm{H}$, Attieh E. Accuracy of clinical fetal weight estimation by Midwives. BMC Pregnancy Childbirth 2017;17(1):59. doi: 10.1186/s12884-017-1242-7.

3. Kadji C,Cannie MM, Van Wettere M, Bevilacqua E, Dutemeyer $\mathrm{V}$, Strizek B, et al. A longitudinal study on fetal weight estimation at third trimester of pregnancy: Comparison of magnetic resonance imaging \& 2-D ultrasound predictions. Fetal Diagn Ther. 2017;42(3):181-188. doi: 10.1159/000453356.

4. Torloni MR, Sass N, Sato JL, Renzi AC, Fukuyama M, Rubia de Lucca P. Clinical formulas, mother's opinion and ultrasound in predicting birth weight. Sao Paulo Med J. 2008;126(3):145-149.

5. Dudley NJ. A systemic review of the ultrasound estimation of fetal weight. Ultrasound Obstet Gynecol. 2005;25(1):8089. doi: 10.1002/uog.1751.

6. Bajracharya J, Shrestha NS, Karci C. Accuracy of prediction of birth weight by fetal ultrasound. Kathmandu Uni Med J. 2012;10(38):74-76.

7. Predanic M, Cho A, Ingrid F, Pellettieri J. Ultrasonographic estimation of fetal weight: Acquiring accuracy in residency. J Ultrasound Med. 2002;21(5):495-500.

8. Chauhan SP, Hendrix NW, Magann EF, Morrison JC, Scardo JA, Berghella V. A review of sonographic estimate of fetal weight: Vagaries of accuracy. J Matern Fetal Neonatal Med. 2005;18(4):211-220. doi: 10.1080/14767050500223465.

9. Dar P, Weiner I, Sofrin O, Sachs GS, Bukovsky I, Arieli S. Clinical and sonographic fetal weight estimates in active labor with ruptured membranes. J Reprod Med. 2000;45(5):390-394.

10. Hendrix NW, Grady CS, Chauhan SP. Clinical vs. sonographic estimate of birth weight in term parturients. A randomized clinical trial. J Reprod Med. 2000;45(4):317-322.

11. Fox Ns, Bhavsar V, Saltzman DH, Rebarber A, Chasen ST. Influence of maternal body mass index on the clinical estimation of fetal weight in term pregnancies. Obstet Gynecol. 2009;113(3):641-645. doi: 10.1097/ AOG.0b013e3181998eef.

12. Faschingbauer F, Raabe E, Heimrich J, Faschingbauer C, Schmid M, Mayr A, et al. Accuracy of sonographic fetal weight estimation: Influence of the scan-to-delivery interval in combination with the applied weight estimation formula. Arch Gynecol Obstet. 2016;294(3):487-493. doi: 10.1007/ s00404-015-3989-2.
13. Faschingbauer F, Heimrich J, Raabe E, Kehl S, Schneider $\mathrm{M}$, Schmid $\mathrm{M}$, et al. Longitudinal $\mathrm{z}$ Score Distribution in Sonographic Fetal Biometry: Influence of Examiner and Experience. J Ultrasound Med. 2017;36(5):1021-1028. doi: 10.7863/ultra.16.06031.

14. Aksoy H, Aksoy U, Karadag OI, Yucel B, Aydin T, Babayigit MA. Influence of maternal body mass index on sonographic fetal weight estimation prior to scheduled delivery. J Obstet Gynaecol Res. 2015;41(10):1556-1561. doi: $10.1111 /$ jog. 12755 .

15. Barnhard Y, Bar-Hava I, Divon MY. Accuracy of intrapartum estimated of fetal weight. Effect of oligohydramnios. J Reprod Med. 1996;41(12):907-910.

16. Noumi G, Collado-Khoury F, Bombard A, Julliard K, Weiner Z. Clinical and sonographic estimation of fetal weight performed during labor by residents. Am J Obstet Gynecol. 2005;192(5):1407-1409. doi: 10.1016/j. ajog.2004.12.043.

17. Melamed N, Ben-Haroush A, Meizner I, Mashiach R, Yogev Y, Pardo J. Accuracy of sonographic fetal weight estimation: a matter of presentation. Ultrasound Obstet Gynecol. 2011;38(4):418-424. doi: 10.1002/uog.8928.

18. Melamed N, Ben-Haroush A, Meizner I, Mashiach R, Glezerman M, Yogev Y. Accuracy of sonographic weight estimation as a function of fetal sex. Ultrasound Obstet Gynecol. 2011;38(1):67-73. doi: 10.1002/uog.8914.

19. Barel O, Maymon R, Vaknin Z, Tovbin J, Smorgick N. Sonographic fetal weight estimation - is there more to it than just fetal measurements? Prenatal Diagn. 2014;34(1):5055. doi: $10.1002 /$ pd.4250.

20. Hadlock FP, Harrist RB, Sharman RS, Deter RL, Park SK. Estimation of fetal weight with the use of head, body and femur measurements - a prospective study. Am J Obstet Gynecol. 1985;151(3):333-337.

21. Ugwa EA, Gaya S, Ashimi A. Estimation of fetal weight before delivery in low-resource setting of Northwest Nigeria: Can we rely on our clinical skills? J Matern Fetal Neonatal Med. 2015;28(8):949-953. doi: 10.3109/14767058.2014.938627.

22. Nahum GG, Stanislaw H. Ultrasonographic prediction of term birth weight: How accurate is it? Am J Obstet Gynecol. 2003;188(2):466-474.

23. Colman A, Maharaj D, Hutton J, Tuohy J. Reliability of ultrasound estimation of fetal weight in term singleton pregnancies. N Z Med J. 2006;119(1241):U2146.

24. Dammer U, Goecke TW, Voigt F, Schmid M, Mayr A, Schild RL, et al. Sonographic weight estimation in fetuses with breech presentation. Arch Gynecol Obstet. 2013;287(5):851858. doi: 10.1007/s00404-012-2653-3.

\section{Authors Contribution:}

EET: Study design and concept, data analyses, data interpretation, drafting and writing.

EAK: Study design and concept, data collection, drafting and writing.

GY: Study design and concept, data collection, drafting and writing.

AFY: Study design, literature search, drafting and writing. 